\title{
Specific bronchial reactivity to toluene diisocyanate: relationship with baseline clinical findings
}

\author{
PL PAGGIARO, A INNOCENTI, E BACCI, O ROSSI, D TALINI
}

From the Institute of Methodology and Occupational Medicine, Pisa; and the Institute of Occupational Medicine, Siena, Italy

\begin{abstract}
One hundred and fourteen subjects with asthma induced by toluene diisocyanate were identified and the pattern of their bronchial responses to challenge with toluene diisocyanate was studied. An occupational type specific bronchial provocation test with toluene diisocyanate (10-25 parts per thousand million for 10-15 minutes) elicited an immediate response in 24 , a late response in 50, and a dual response in 40 patients. Subjects with a dual response showed at diagnosis a longer duration of symptoms and a greater prevalence of airway obstruction; in these subjects FEV 1 (percentage of predicted value) was lower than in subjects with immediate or late reactions to toluene diisocyanate. The percentage of current smokers and ex-smokers was significantly lower in subjects with a late response $(26 \%)$ than in subjects with immediate or dual responses $(56 \%$ and $57 \%$ respectively). In 27 of the 114 subjects a non-specific challenge test with methacholine was performed and subjects with dual responses showed greater non-specific bronchial hyperresponsivess than the other groups. These results suggest that a dual response to specific challenge in bronchial asthma related to toluene diisocyanate may be associated with more severe disease than other types of response, as assessed by duration of symptoms, baseline airway obstruction, and non-specific bronchial hyperresponsiveness. The high prevalence of non-smokers and low prevalence of smokers in the group with a late response to specific challenge is so far unexplained.
\end{abstract}

Toluene diisocyanate, a component of polyurethane varnish, frequently causes bronchial asthma in exposed workers. ${ }^{1}$ In workers in the furniture industry in Tuscany, asthma related to toluene diisocyanate has been estimated to develop in about $1.5 \%$ of the exposed work force each year. ${ }^{2}$ Toluene diisocyanate exposure during a bronchial provocation test may produce an immediate bronchospastic reaction, an isolated late reaction, or a dual (both immediate and late) reaction. ${ }^{3}$ The pathogenetic mechanisms and the clinical importance of the different patterns of response to specific provocation testing are not completely clear. Some authors ${ }^{4-6}$ suggest that a dual response is associated with greater severity of disease or with greater non-specific bronchial hyperresponsiveness than is an immediate reaction. ChanYeung and colleagues ${ }^{78}$ observed that asthmatic

Address for reprint requests: Dr PL Paggiaro, Clinica Medica 2, Fisiopatologia Respiratoria, c/o Ente Ospedaliero di Pisa, via Roma 57, 56100 Pisa, Italy.

Accepted 22 October 1985 patients with dual responses to a challenge test with red cedar wood dust showed more advanced disease than others at the time of diagnosis and an unfavourable prognosis after removal from occupational exposure.

The aim of this study was to assess whether the pattern of response to challenge testing correlates with any particular clinical feature of the disease, such as baseline airway obstruction or the level of non-specific bronchial hyperresponsiveness.

\section{Methods}

Among 270 workers in the furniture industry investigated from 1976 to 1982 in two centres in Tuscany (the Institutes of Occupational Medicine of Pisa and Siena) because of respiratory symptoms in workers, 114 patients with bronchial asthma induced by toluene diisocyanate were identified. All experienced dyspnoea and wheezing when exposed to polyurethane varnish containing toluene diisocyanate and all showed a positive response to specific provocation testing. The patients were examined during a stable 
Table 1 Clinical findings in the workers with immediate, late, and dual reactions to challenge with toluene diisocyanate

\begin{tabular}{|c|c|c|c|}
\hline & Immediate & Late & Dual \\
\hline $\begin{array}{l}\text { Number of subjects } \\
\text { Mean (SD) age (y) } \\
\text { Male (\%) } \\
\text { Smoking habit: }\end{array}$ & $\begin{array}{l}24 \\
44.7(11.6) \\
79\end{array}$ & $\begin{array}{l}50 \\
46.2(11.7) \\
76\end{array}$ & $\begin{array}{l}40 \\
47.1(11.9) \\
72\end{array}$ \\
\hline $\begin{array}{l}\text { Current smoker (\%) } \\
\text { Ex-smoker (\%) } \\
\text { Non-smoker (\%) } \\
\text { Atopy }(\%) \\
\text { Had given up work (\%) } \\
\text { Mean (SD) duration of symptoms (y) } \\
\text { Chronic bronchitis (\%) }\end{array}$ & $\begin{array}{l}37.5 \\
16.6 \\
45.8 \\
23 \\
18 \\
3.6(3.9) \\
21\end{array}$ & $\begin{array}{l}12.5 \\
12.5 \\
75.0+ \\
14 \\
10 \\
2.6(2.5) \\
16\end{array}$ & $\begin{array}{l}17.9 \\
41.0 \dagger \\
41.0 \\
25 \\
18 \\
5.1(4.3)^{*}\end{array}$ \\
\hline
\end{tabular}

* Significantly longer than the other two groups ( $<<0.05$, Kruskall-Wallis test).

+Significantly greater than the other two groups (p $<0.01,2 \times 3 \chi^{2}$ test).

period of the disease; bronchodilator drugs were withdrawn $\mathbf{4 8}$ hours before the challenge, and no patient was having regular treatment with steroids.

A few days before challenge with toluene diisocyanate all patients were evaluated with regard to (1) respiratory symptoms and smoking habit; subjects were divided into current smokers, ex-smokers of at least six months' duration and with a previous consumption of more than three pack years and nonsmokers; (2) baseline pulmonary function tests (VC, $\mathrm{FEV}_{1}$, and $\mathrm{FEV}_{1} / \mathrm{VC} \%$ ) (Pulmotest Godard), the predicted values being derived from those published by the European Coal and Steel Community'; (3) atopy, defined as one or more positive reactions (wheal $>5 \mathrm{~mm}$ ) to skinprick tests with 11 common allergens; (4) non-specific bronchial hyperresponsivesness: this was evaluated in all patients with various agents used in single dose (acetylcholine, histamine, bethanechol) but only in the last 27 subjects was a standardised measurement using methacholine performed. For this, methacholine was inhaled from a Bird Mark 7 device connected to an electronic dosimeter (output $0.01 \mathrm{ml}$ over 0.6 seconds in each inhalation), in steps of increasing amount from 25 to $2000 \mu \mathrm{g}$ until a fall in $\mathrm{FEV}_{1}$ exceeding $20 \%$ was observed; the provocative dose causing a $20 \%$ fall in $\mathrm{FEV}_{1}\left(\mathrm{PD}_{20} \mathrm{FEV}_{1}\right)$ was calculated from the log doseresponse curve. ${ }^{10}$

Specific challenge testing was always performed after the other tests and consisted of spray or brush painting with two spot polyurethane varnish for
10-15 minutes in a cabin of $12 \mathrm{~m}^{3}$ (occupation type test) ${ }^{11}$; toluene diisocyanate concentration in the $y$ cabin was measured by the Marcali method ${ }^{12}$ or by an 0 MDA 7005 toluene diisocyanate detector and ranged? from 15 to 25 parts per $10^{9}(\mathrm{ppb})$; this concentrationis in accordance with the American Conference Gov $\frac{7}{0}$ ernment industrial hygiene threshold limit value for toluene diisocyanate of $20 \mathrm{ppb}$ for 15 minutes. The $\overrightarrow{0}$ highest values in the present study were obtainedos when the Marcali method was used in the earlier cases.o No differences were observed between the concentrations resulting from spray and from brush painting. Before and 15, 30, and 60 minutes after the challengen $\mathrm{FEV}_{1}$ was recorded and the measurement was re-क्ष peated each hour up to 8 hours; a fall in $\mathrm{FEV}_{1}$ greater than $15 \%$ was considered as a positive response. Theo responses were classified as immediate (fall in FEV within the first hour after the challenge), late (between the second and the seventh to eighth hour following toluene diisocyanate exposure), and dual (both immediate and late). Control tests were performed్ with varnish containing no activator or diluent.

Statistical analysis was performed with the $\chi^{2}$ test analysis of variance, or Kruskall-Wallis test (a nonparametric test) as appropriate.

\section{Results}

Clinical findings in the 114 examined workers are re ported in table 1. A slight predominance of late reace tions was observed. There were no significan $\mathbb{O}$

Table 2 Prechallenge airway function of workers with immediate, late and dual reactions to toluene diisocyanate

\begin{tabular}{|c|c|c|c|}
\hline & Immediate & Late & Dual \\
\hline $\begin{array}{l}\text { Number } \\
\text { VC mean (SD) (\% predicted) } \\
\text { FEV, mean (SD) (\% predicted) } \\
\text { FEV, } / \text { VC mean (SD) }(\%) \\
\text { Airway obstruction* }(\%)\end{array}$ & $\begin{array}{l}24 \\
98.0(13.1) \\
96.3(17.2) \\
74.1(10.0) \\
4\end{array}$ & $\begin{array}{l}50 \\
97.9(15.5) \\
91.2(21.2) \\
69.9(10.2) \\
26\end{array}$ & $\begin{array}{l}40 \\
96.2(14.9) \\
87.2(19.9) \dagger \\
68.4(11.4) \\
35 t\end{array}$ \\
\hline $\begin{array}{l}\text { *For definition see text. } \\
t \mathrm{p}<0.05 \text { (ANOVA). } \\
\ddagger \mathrm{p}<0.01 \text { ( } 2 \times 3 \chi^{2} \text { test). }\end{array}$ & & & \\
\hline
\end{tabular}


$\mathbf{P D}_{20}$

(mg)

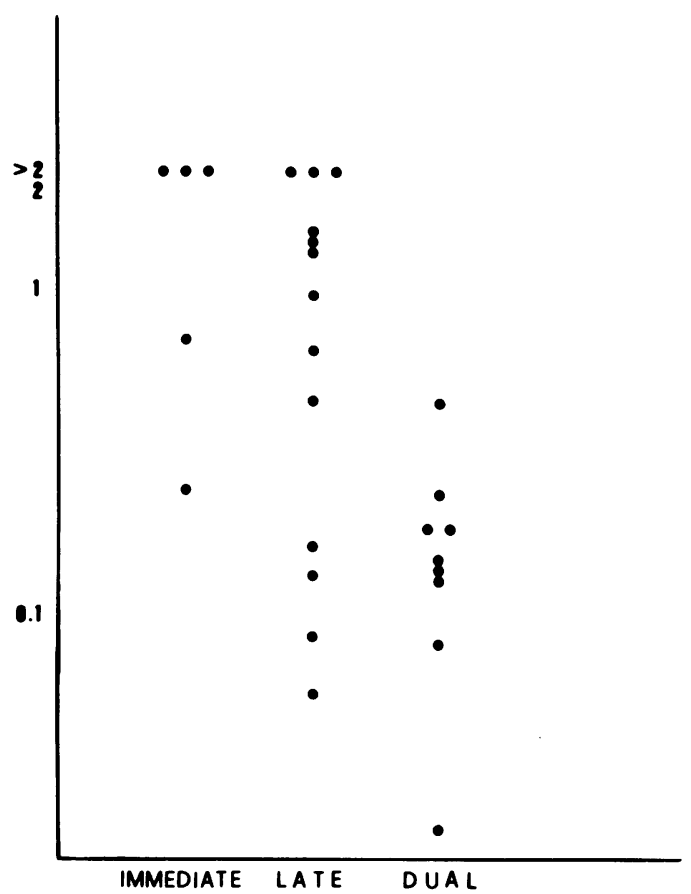

Non-specific bronchial hyperresponsiveness to methacholine (expressed as $P D_{20} F E V_{1}$ - the concentration causing a $20 \%$ fall in $F E V_{1}$ ) in 27 subjects with immediate, late, and dual reactions to specific challenge with toluene diisocyanate.

differences in the mean ages, the male:female ratio, or the prevalence of atopy or chronic bronchitis ("chronic or recurrent bronchial hypersecretion, clinically diagnosed by the presence of chronic expectoration with no other cause" ${ }^{13}$ ) among the three groups with different patterns of positive response to challenge with toluene diisocyanate. When smoking habit was considered, a significantly lower percentage of smokers in the late reaction group was observed; there was no significant difference in consumption of tobacco (expressed as pack years) among current smokers or ex-smokers between the three groups. Sixteen subjects had stopped work at least two months before the specific challenge testing was performed, but they were equally distributed between the three groups of responders. Subjects with a dual response had a significantly longer duration of symptoms before diagnosis than those in the other groups.

Table 2 shows spirometric findings in the workers with immediate, late, and dual reactions to challenge with toluene diisocyanate. A significant difference in
$\mathrm{FEV}_{1}$ between the three groups was observed, subjects with dual reactions to toluene diisocyanate showing the lowest mean value. Airway obstruction, defined as a value of $\mathrm{FEV}_{1} / \mathrm{VC} \%$ lower than two standard deviations below the mean for sex and age, was significantly more frequent in subjects with a dual response, whereas few subjects with an immediate response showed airway obstruction before challenge.

Bronchial hyperresponsiveness to methacholine, expressed as $\mathrm{PD}_{20} \mathrm{FEV}_{1}$, in 27 workers is shown in the figure. Subjects with a dual response showed more obvious bronchial hyperresponsiveness than subjects with immediate or late responses. Comparison of the values of $\log \mathrm{PD}_{20} \mathrm{FEV}_{1}$ in the three groups shows a significantly lower mean value in subjects with a dual response. When the 27 subjects in whom methacholine challenge testing was performed were compared with the remaining 87 workers, no significant differences in clinical and functional findings were observed except for the duration of symptoms, which was longer in the subgroup of 27 subjects.

\section{Discussion}

A late response to inhaled agents is frequently observed during challenge testing, mainly in asthma due to occupational agents such as diisocyanates. According to the criteria of other authors, ${ }^{56814} 80 \%$ of our subjects with positive responses showed a late or dual response to toluene diisocyanate challenge testing. Recent studies suggest that the late reaction is of clinical importance, because it is generally more severe and prolonged than the early reaction, it is responsive to steroids, ${ }^{15}$ and, unlike the immediate response, it may induce a persistent increase in nonspecific bronchial hyperresponsiveness. ${ }^{1617}$ It is not clear, however, how the patient who shows a late reaction differs from one who does not.

Our results suggest that in asthmatic subjects sensitive to toluene diisocyanate those with a dual reaction at the time of diagnosis have a greater degree of airway obstruction and more evident non-specific bronchial hyperresponsiveness than do subjects with immediate or late reactions. This finding is not related to differences in age or to the presence of chronic bronchitis or atopy among the three groups with different patterns of response to toluene diisocyanate. In most of our patients specific challenge tests were performed only a short time (less than two months) after cessation of occupational exposure to toluene diisocyanate. It is well known that the cessation of occupational exposure to a sensitising agent may modify airway calibre or bronchial reactivity ${ }^{71819}$; only $14 \%$ of our subjects had been out of work for two months or more at the time when specific challenge 
testing was performed, and this proportion was similar in the three groups with different patterns of response.

The duration of asthmatic symptoms at the time of diagnosis was greater in subjects with a dual response than in those with immediate or late reactions; this suggests that a dual reaction to toluene diisocyanate might indicate a more advanced stage in the natural history of bronchial asthma provoked by toluene diisocyanate. Longitudinal studies would, however, be required to study the relationship between bronchial responsiveness to toluene diisocyanate and progression of the disease.

The low prevalence of smoking in the subjects with a late reaction to toluene diisocyanate suggests that the irritant effect of cigarette smoke may favour the development of an immediate response to toluene diisocyanate. It is well recognised that bronchial asthma is in general more frequent in non-smokers and it sometimes appears after the cessation of smoking $^{20}$; the low prevalence of smoking in subjects with a late reaction to toluene diisocyanate, however, is not readily explained. It may be related to the increase in permeability of the airway mucosa that has been observed in smokers ${ }^{21}$ or to differences in the amount of preformed or newly synthesised chemical mediators in the airway mucosa between smokers and non-smokers. ${ }^{22}$ Thus cigarette smoking might cause an increased release of preformed mediators after specific challenge testing, which could result in an immediate type reaction. Further study of the permeability of airway mucosa and of the chemical mediators of airway responsiveness in patients with immediate, late, and dual reactions to toluene diisocyanate might therefore be useful in understanding the clinical and pathogenetic importance of the different patterns of bronchial response to isocyanates.

\section{References}

1 Pepys J, Pickering CAC, Breslin ABX, Terry DJ. Asthma due to inhaled chemical agents-toluene diisocyanate. Clin Allergy 1972;2:225-36.

2 Innocenti A, Sartorelli E. Incidence of TDI asthma among wood painters and predictive value of methacholine tests [abstract]. In: Proceedings of International Symposium on Prevention of Allergic Diseases, Florence. Firenze: Organizzazione Internazionale Congressi Medical Press, 1984:174.

3 Pepys J, Hutchcroft BJ. Bronchial provocation tests on etiological diagnosis and analysis of asthma. Am Rev Respir Dis 1975;112:829-59.
4 Warner JO. Significance of late reactions after bronchia challenge with house dust mite [abstract]. Arch Dis Child: 1976;51:905.

5 Booij-Noord H, DeVries K, Slueter HJ, Orie NGM. Late bronchial obstructive reaction to experimental inhalation of house dusts extracts. Clin Allergy 1972;2:43-61.

6 Harries MG, Burge PS, O'Brien I. Bronchial provocation testing: relationship between the pattern of the asthmatic response and histamine sensitivity of the airway [ab stract]. Bull Eur Physiopathol Respir 1985;21:21A.

7 Chan-Yeung M. Fate of occupational asthma. Am Re $\vec{b}$ Respir Dis 1977;116:1023-9.

8 Chan-Yeung M, Lam S, Koener S. Clinical features anc natural history of occupational asthma due to Western red cedar (Thuja plicata). Am J Med 1982;72:411-5. 穴

9 Bolt W, Cara M, Coppè G, et al. Promemoria tecnico per l'esame della funzione ventilatoria con la spirografia Luxembourg: European Coal and Steel Community 1961.

10 Innocenti A, Mancini R, Franzinelli A, Sartorelli E Reattività bronchiale $\mathrm{e}$ asma da isocianati. Medicina Tor옥 acica 1982;4:161-5.

11 Zedda S, Cirla AM, Aresini G, Sala C. Occupational type test for the etiological diagnosis of asthma due to toluene. diisocyanate. Respiration 1976;33:14-21.

12 Marcali K. Microdetermination of toluene diisocyanat $\vec{e}$ in the atmosphere. Anal Chem 1957;29:552-8.

13 Ciba Guest Symposium. Terminology, definitions and classifications of chronic pulmonary emphysema anf related conditions. Thorax 1959;14:286-99.

14 Mapp C, Moro G, Fabbri L, Crepet M. Asma da toluen? diisocianato: studi di provocazione bronchiale specifica aspecifica. Med Lav 1979;7:203-14.

15 Fabbri LM, Chiesura P, Dal Vecchio L, et al. Prednisone inhibits late asthmatic reaction and the associate $\vec{f}$ increase in airway responsiveness induced by toluenes diisocyanate in sensitized subjects. Am Rev Respir Dis $1985 ; 132: 1010-4$.

16 Cockcroft DW. Mechanism of perennial asthma. Lanceit 1983;i:252-6.

17 Cartier A, Thomson NC, Frith PA, Roberts R Hargreave FE. Allergen-induced increase in bronchiak responsiveness to histamine: relationship to the late asthe matic response and change in airway caliber. $J$ Allerg $\vec{y}$. Clin Immunol 1982;70:170-7.

18 Paggiaro PL, Loi AM, Rossi O, et al. Follow-up study of patients with respiratory disease due to toluene diisocyanate (TDI). Clin Allergy 1984;14:463-9.

19 Lam S, Wong R, Chan-Yeung M. Non specific bronchiad reactivity in occupational asthma. J Allergy Clin Immi nol 1979;63:28-34.

20 Hillerdhal G, Rylander R. Asthma and cessation of smoking. Clin Allergy 1984;14:45-7.

21 Kennedy SM, Elwood RK, Wiggs BJK, Parè PD, Hog尽 JC. Increased airway permeability of smokers. Relationsu ship to airway reactivity. Am Rev Respir Dis 1984;129 143-8.

22 Kaliner M. Hypotheses on the contribution of late-phase allergic responses to the understanding and treatment oh allergic diseases. J Allergy Clin Immunol 1984;73:311-5. 